\title{
STRUKTUR KOMUNITAS DAN PRODUKTIVITAS EKOSISTEM PADANG LAMUN DI PULAU PANNIKIANG SULAWESI SELATAN
}

\author{
(Community Structure and Productivity of Seagrass Bed Ecosystem in \\ Pannikiang Island, South Sulawesi, Indonesia) \\ Lizha Dwi Mulya Putri ${ }^{1)}$, Abdul Rauf ${ }^{2)}$ dan Hamsiah' ${ }^{2)}$ \\ ${ }^{1)}$ Mahasiswa Pascasarjana Universitas Muslim Indonesia Makassar \\ ${ }^{2)}$ Program Studi Ilmu Kelautan FPIK UMI Makassar \\ Korespondensi: lizhadwimulyap@gmail.com
}

Diterima: tanggal 25 Agustus 2019; disetujui: 25 September 2019

\begin{abstract}
This research was conducted with the aim of: Analyzing community structure and productivity of seagrasses. The research was conducted in August to November 2018. Data analysis included community structure analysis and seagrass productivity, then tested using One-Way ANOVA and Duncan's advanced test using the SPSS version 15 program. The results of this study indicate that: Seagrass communities on Pannikiang Island consist of the types Enhalus acoroides, Halophila ovalis, and Cymodocea rotundata, which are dominated by Enhalus acoroides. The type of muddy substrate and seen from its nutrient content, can be categorized in water conditions that are suitable for seagrass life. The result of INP calculation is dominated by Enhalus acoroides, while the highest productivity (biomass) is found in the type of Enhalus acoroides.
\end{abstract}

Keywords : Seagrass, Community Structure, Seagrass Productivity, SPSS

\begin{abstract}
ABSTRAK
Penelitian ini dilakukan dengan tujuan untuk menganalisis struktur komunitas dan produktivitas ekosistem padang lamun di Pulau Pannikiang, Sulawesi Selatan, Indonesia. Penelitian ini dilaksanakan pada bulan Agustus sampai November 2018. Data struktur komunitas dan produktivitas lamun dianalisis, kemudian diuji menggunakan One-Way ANOVA dan uji lanjut Duncan menggunakan program SPSS versi 15. Hasil penelitian ini menunjukkan komunitas lamun di lokasi penelitian terdiri dari jenis Enhalus acoroides, Halophila ovalis, dan Cymodocea rotundata. Jenis substrat yan dijumpai dalam transek pengamatan adalah pasir berlumpur dengan kandungan nutrien yang sesuai untuk kehidupan lamun. Hasil perhitungan INP didominasi oleh Enhalus acoroides, sedangkan produktivitas (biomassa) tertinggi terdapat pada jenis Enhalus acoroides.
\end{abstract}

Kata Kunci : Struktur Komunitas Lamun, Produktivitas Lamun, SPSS 


\section{PENDAHULUAN}

Ekosistem lamun merupakan produsen primer dalam rantai makanan di perairan laut dengan produktivitas primer berkisar antara 900-4650 gC/m²/tahun. Sejak tahun 1980 sampai sekarang, diperkirakan lamun di dunia telah mengalami degradasi 54 \% (Bjork et al. 2008). Fungsi ekosistem lamun sebenarnya melengkapi ekosistem mangrove dan terumbu karang, dimana dapat dilihat dari variasi keanekaragaman iktiofuna berdasarkan konektifitasnya dengan ekosistem mangrove dan terumbu karang (Latuconsina et al, 2019). Sebelumnya sudah diketahui keutamaan ekosistem mangrove dan terumbu karang, diantaranya memiliki jumlah kenekaragman hayati e.g. ikan, krustacea, molusca yang tinggi (Akbar et al. 2018; Faisal et al. 2019; Putriningtias et al. 2019). Nilai ekonomi dan fungsi suatu ekosistem padang lamun juga diketahui sangat besar baik meliputi kegiatan penangkapan ikan, penunjang ekowisata, dan penyerap karbon (Oktawati et al. 2018; Hartini dan Lestarini, 2019; Ganefiani et al. 2019).
Ekosistem padang lamun yang beranekaragam serta berlimpahnya organisme yang beraososiasi dengan ekosistem lamun dapat dimanfaatkan sebagai tempat pemancingan, wisata bahari, bahan baku pakan buatan untuk ikan dan hewan ternak, sumber pupuk hijau, areal marikultur (ikan, teripang, karang, tiram dan rumput laut), bahan baku kerajinan anyaman, dan sebagainya (Dahuri et al. 2001).

Pertumbuhan dan kepadatan lamun sangat dipengaruhi oleh pola pasang surut, turbiditas, salinitas dan temperatur perairan. Kegiatan manusia di wilayah pesisir seperti perikanan, pembangunan perumahan, pelabuhan dan rekreasi, baik langsung maupun tidak langsung juga dapat mempengaruhi eksistensi lamun. Oleh karena itu segala bentuk perubahan di wilayah pesisir akibat aktivitas manusia yang tidak terkontrol dapat menimbulkan fungsi sistem ekologi ekosistem lamun. Fenomena ini akan berpengaruh terhadap hilangnya unsur lingkungan seperti daerah pemijahan (spawning ground), pembesaran (nursery ground) bagi ikan maupun udang. Adapun tujuan dari penelitian ini adalah untuk mengetahui struktur komunitas dan produktifitas lamun di 
Pulau Pannikiang Kabupaten Barru, Sedangkan analisis data biomassa Provinsi Sulawesi Selatan, Indonesia.

\section{MATERI DAN METODE}

Penelitian ini dilaksanakan pada bulan Agustus - November 2018 di wilayah pesisir Pulau Pannikiang, Kecamatan Balusu, Kabupaten Barru, Provinsi Sulawesi Selatan (Gambar 1). lamun dan substrat dasar dilakukan di Laboratorium Ilmu Tanah dan Laboratorium Oseanografi, Fakultas Ilmu Kelautan dan Perikanan Universitas Hasanuddin. Dan pengolahan data citra dilakukan di Balai Penginderaan Jauh Pare-Pare.

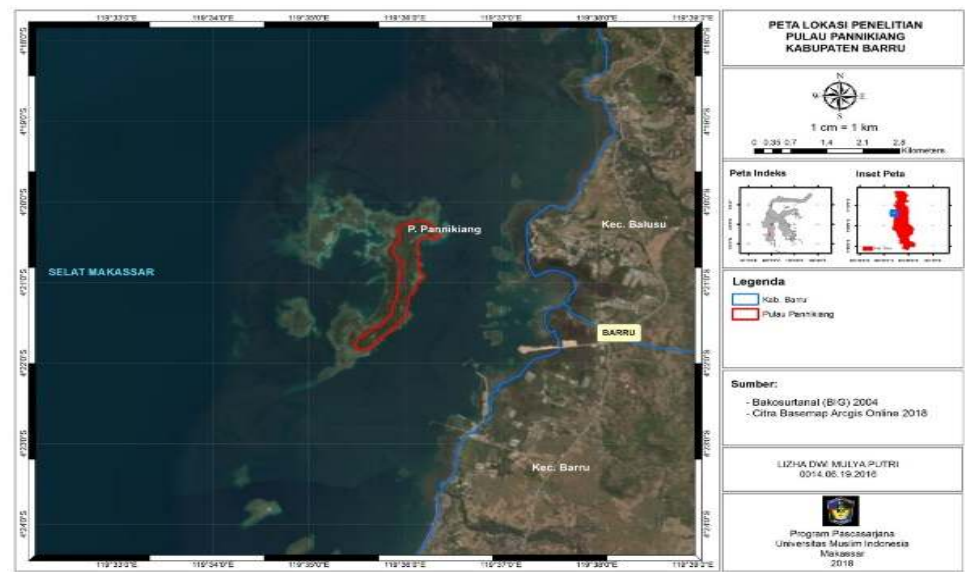

Gambar 1. Peta Lokasi Penelitian

Adapun alat dan bahan yang digunakan dalam penelitian disajikan pada Tabel 1.

Tabel 1. Alat dan bahan

\begin{tabular}{|c|c|c|c|}
\hline Parameter & Satuan & Alat \& Bahan & Keterangan \\
\hline \multicolumn{4}{|l|}{ Fisika } \\
\hline Suhu & ${ }^{\circ} \mathrm{C}$ & Termometer & In Situ \\
\hline Kedalaman & $\mathrm{cm}$ & Meteran Roll & In Situ \\
\hline Salinitas & Ppm & Hand Refractometer & In Situ \\
\hline Kekeruhan & NTU & Turbidimeter & Laboratorium \\
\hline \multicolumn{4}{|l|}{ Kimia } \\
\hline Oksigen Terlarut & $\mathrm{Mg} / 1$ & Bahan titrasi & In Situe \\
\hline PH & - & PH Meter & In Situ \\
\hline Nitrat & $M g / 1$ & Spektrofotometer & Laboratorium \\
\hline Fosfat & $\mathrm{Mg} / \mathbf{1}$ & Spektrofotometer & Laboratorium \\
\hline \multicolumn{4}{|l|}{ Biologi } \\
\hline Kerapatan & Individu/m $/ \mathbf{m}^{2}$ & Kuadran & In Situ \\
\hline Frekuensi & $\%$ & Kuadran & In Situe \\
\hline Penutupan & $\%$ & Kuadran & In Situ \\
\hline Biomassa & gram & Timbangan, oven & Laboratorium \\
\hline \multicolumn{4}{|l|}{ Cain-Lain } \\
\hline Dokumentasi & & Kamera underwater & In Situ \\
\hline Uji transek & & Transek & In Situ \\
\hline Untuk menjangk: & aerah & Perahu Motor & In Situ \\
\hline \multicolumn{4}{|c|}{ penelitian } \\
\hline Mengambil titik 1 & dinat & GPS & In Situ \\
\hline Pengolahan data & & PC & \\
\hline
\end{tabular}


Teknik pengambilan contoh secara Purposive Sampling. Tahapan penelitian dilakukan dengan persiapan penelitian meliputi survey lapangan yang kemudian dilanjutkan dengan penentuan stasiun penelitian, pengambilan sampel lamun dan substrat serta beberapa parameter pendukung berupa data kualitas air dan dokumentasi di lokasi terpilih. Kemudian dilakukan analisis di Laboratorium. Sampel lamun diidentifikasi sesuai dengan deskripsi Mc Kenzie (2003), Irawan (2017), dan Supriyadi et al. (2018).

Teknik penentuan sampel yang digunakan adalah purposive sampling yaitu cara pengambilan sampel atau penentuan sampel dengan menetapkan ciri yang sesuai dengan tujuan, dimana teknik pengambilan sampel masingmasing stasiun dapat mewakili wilayah penelitian secara keseluruhan sehingga memperkecil terjadinya bias terhadap data yang diperoleh.

\section{Kerapatan Jenis}

Kerapatan jenis (Ki) lamun adalah jumlah total individu dalam satu unit area (English et al. 1994).

$$
K i=\frac{N i}{A}
$$

Keterangan :

$\mathrm{Ki}=$ Kerapatan jenis $\left(\mathrm{ind} / \mathrm{m}^{2}\right)$

$\mathrm{Ni}=$ Jumlah total tegakan individu spesies ke-i

$\mathrm{A}=$ Luas area total pengambilan sampel

\section{Kerapatan Relatif}

Kerapatan relatif (KRi) merupakan perbandingan antara jumlah individu jenis ke - i dengan jumlah total individu seluruh jenis (English et-al. 1994).

$$
K R i=\frac{N i}{\sum n} \times 100
$$

Keterangan :

Kri $=$ Kerapatan jenis relatif

$\mathrm{Ni}=$ Jumlah total tegakan individu spesies ke-i

$\sum n=$ Jumlah total tegakan seluruh spesies

\section{Frekuensi Jenis}

Frekuensi jenis adalah peluang ditemukannya suatu jenis lamun dalam area yang diamati.

$$
F i=\frac{P i}{\sum_{t=1}^{p} P i}
$$

Keterangan :

$\begin{array}{ll}\mathrm{Fi} & \text { : Frekuensi spesies ke-i } \\ \mathrm{Pi} & \begin{array}{l}\text { : Jumlah petak contoh } \\ \text { dimana ditemukan } \\ \end{array} \\ \sum_{t=1}^{p} \mathrm{Pi} & \text { spesies ke-i } \\ & \text { Jumlah total petak }\end{array}$


contoh yang diamati

\section{Frekuensi Relatif}

Frekuensi relatif (FRi) merupakan perbandingan antara frekuensi jenis ke-i (Fi) dengan frekuensi seluruh jenis (Brower et al. 1988).

$$
F R i=\frac{F i}{\sum_{t=1}^{p} F i} \times 100
$$

Keterangan :

FRi

Fi : Frekuensi spesies ke-i

$\sum_{t=1}^{p} F i \quad: \quad$ Jumlah Frekuensi seluruh spesies

\section{Penutupan Jenis}

Tabel 2. Etimasi/penilaian tutupan lamun
Menurut English et al. 1994, untuk menentukan persentase tutupan (Ci) pada setiap 50 x 50 kuadran adalah menggunakan rumus sebagai berikut dan estimasi tutupan terdapat pada tabel 2 :

$$
C i=\frac{\sum(M i x f i)}{\sum f i}
$$

Keterangan :

Mi : Mid Point (titik tengah) $1 / 4$

Fi : Frekuensi kemunculan spesies ke-i

$\sum f i \quad:$ Jumlah total frekuensi kemunculan seluruh spesies

\begin{tabular}{cccc}
\hline Class & $\begin{array}{c}\text { Jumlah substratum yang } \\
\text { ditutupi }\end{array}$ & $\begin{array}{c}\text { \% substratum yang } \\
\text { ditutupi }\end{array}$ & $\begin{array}{c}\text { Titik tengah } \\
(\mathrm{Mi})\end{array}$ \\
\hline 5 & $1 / 4-$ seluruh & $50-100$ & 75 \\
4 & $1 / 4-1 / 1 / 8-1 / 4$ & $25-50$ & 37,5 \\
3 & $1 / 8,16-25-25$ & 18,75 \\
2 & $1 / 11 / 8$ & $6,25-12,5$ & 9,38 \\
1 & $<1 / 16$ & $<6,25$ & 3,13 \\
0 & Tidak ada lamun & 0 & 0 \\
\hline
\end{tabular}

\section{Penutupan Relatif}

Persentase penutupan relatif (CRi) merupakan perbandingan antara penutupan individu jenis ke-i dengan jumlah penutupan seluruh jenis seperti yang dirumuskan oleh Mc Kenzie and Yoshida (2009) sebagai berikut:

$$
C R i=\frac{C i}{\sum_{t=1}^{p} C i} \times 100
$$

Keterangan :

Cri : Penutupan relatif
$\mathrm{Ci}$ : Luas area yang tertutupi spesies ke-i $\sum_{t=1}^{p} C i \quad$ : Penutupan seluruh spesies

\section{Indeks Nilai Penting}

INP memberikan gambaran mengenai pengaruh atau peranan suatu jenis tumbuhan terhadap suatu daerah.

$$
\mathrm{INP}=\mathrm{KRi}+\mathrm{FRi}+\mathrm{CRi}
$$

Keterangan :

Kri $=$ Kerapatan relatif 
$\mathrm{FRi}=$ Frekuensi relatif

$\mathrm{CRi}=$ Penutupan relative

\section{Produktifitas Lamun}

Produktifitas lamun melalui pengukuran biomassa lamun adalah berat dari semua material yang hidup pada suatu tertentu, baik yang berada di atas maupun di bawah substrat yang sering dinyatakan dalam satuan gram berat kering per $\mathrm{m}^{2}\left(\mathrm{gbk} / \mathrm{m}^{2}\right)$ (Zieman \& Wetzel, 1980).

$$
B=\frac{W}{A}
$$

Keterangan :

B : Biomassa lamun (berat dalam gram $/ \mathrm{m}^{2}$ )

W : Berat kering (gram)

A : Luas area dalam $\mathrm{m}^{2}$

\section{Parameter Fisika Kimia Perairan}

Pengukuran parameter kualitas air dilakukan dengan cara pengukuran langsung di lapangan (In Situ). Parameter yang diukur secara langsung di lapangan meliputi suhu, kedalaman salinitas, $\mathrm{pH}$ dan oksigen terlarut. Sedangkan substrat dasar diambil dengan menggunakan pipa paralon dengan diameter tiga inci dari tiga lokasi dalam setiap stasiun, kemudian dimasukkan kedalam kantong plastik untuk dianalisis di laboratorium. Substrat dibagi dalam tujuh fraksi (pasir kasar sekali, pasir kasar, pasir sedang, pasir halus, pasir halus sekali, debu dan liat). Penentuan setiap fraksi tersebut menggunakan metode pipet dan gravitasi. Pada penentuan tipe substrat ke tujuh fraksi tersebut digabung menjadi tiga fraksi (pasir, debu, dan liat) dan dikelompokkan dalam segitiga Millar (Brower \& Zar 1977). Penentuan konsentrasi nitrat, fosfat dan C-organik sedimen adalah dengan mengambil sedimen sampai kedalaman $30 \mathrm{~cm}$ dengan corer pada seluruh stasiun pengamatan, kemudian dimasukkan kedalam plastik sampel untuk dibawa ke laboratorium. Selama pengangkutan dari lapangan ke laboratorium dimasukkan ke dalam cool box yang di dalamnya berisi es, yang kemudian dibawa ke laboratorium untuk uji fosfat, nitrat, dll.

Data faktor lingkungan, struktur komunitas dan biomassa lamun antar stasiun diuji dengan ANOVA (Analisis of Varians). Apabila didapatkan hasil yang berpengaruh nyata, akan dilanjutkan dengan uji lanjut Duncan dengan menggunakan program SPSS (Statistical Program Software System) versi 17. 


\section{HASIL DAN PEMBAHASAN}

Pulau Pannikiang merupakan salah satu dari lima pulau kecil yang berada di Kabupaten Barru. Pulau ini masuk dalam Dusun Pannikiang, Desa Madello, Kecamatan Balusu, Kabupaten Barru. Secara geografis Pulau Pannikiang terletak antara $04^{\mathrm{O}} 19^{\prime} 45.21^{\prime \prime}$ $04^{\mathrm{O}} 22^{\prime} 19.93^{\prime \prime}$ LS dan $119^{\mathrm{O}} 34^{\prime} 32.45^{\prime \prime}$ $119^{\mathrm{O}} 36^{\prime} 46.22$ " BT.

\section{Komposisi Jenis, Kerapatan Jenis dan Kerapatan Relatif}

Hasil identifikasi jenis lamun yang ditemukan di perairan Pulau Pannikiang adalah 3 jenis lamun dari family Hydrocharitaceae yang terdiri dari Enhalus acoroides dan Halophila ovalis serta 1 jenis lamun dari family Cymodoceae yaitu Cymodocea rotundata.

Tabel 3. Rata-rata kerapatan Jenis Lamun

\begin{tabular}{|c|c|c|c|c|}
\hline \multirow{2}{*}{ Jenis Lamun } & \multicolumn{3}{|c|}{ Stasiun } & \multirow{2}{*}{ Rata-rata } \\
\hline & I & II & III & \\
\hline Enhalus acoroides* & 152.00 & 100.00 & 156.00 & 136 \\
\hline halophila ovalis & 0.00 & 8.00 & 0.00 & 2.67 \\
\hline Cyomodocea rotundata & 0.00 & 0.00 & 48.00 & 16 \\
\hline Jumlah & 152.00 & 108.00 & 204.00 & 154.67 \\
\hline
\end{tabular}

Hasil analisis kerapatan jenis memperlihatkan bahwa kerapatan tertinggi ditemukan pada jenis $E$. acoroides kemudian disusul oleh $C$. rotundata. Sedangkan kerapatan yang terendah Halophila ovalis yang hanya ditemukan pada stasiun II. Berdasarkan hasil analisis sidik ragam (ANOVA) kerapatan jenis lamun antar stasiun pada jenis lamun E.acoroides memberikan perbedaan yang nyata $(\mathrm{p}<0,05)$ sedangkan pada jenis H.ovalis dan C.rotundata tidak memberikan perbedaan nyata $(\mathrm{p}>0,05)$

\section{Frekuensi Jenis dan Frekuensi}

\section{Relatif}

Secara keseluruhan nilai rata-rata frekuensi jenis di dominasi oleh lamun yang berukuran besar yaitu $E$. acoroides pada seluruh stasiun pengamatan dengan rata-rata stasiun I dan stasiun II sebesar $3,00 \%$, disusul dengan jenis yang sama pada stasiun III sebesar $2.75 \%$. Sedangkan untuk frekuensi terendah terdapat pada jenis $H$. ovalis sebesar $0.50 \%$. Berdasarkan hasil analisis sidik ragam (ANOVA) frekuensi jenis lamun antar stasiun pada ketiga jenis lamun 
tidak memberikan perbedaan yang nyata $\quad(p>0,05)$.

Tabel 4. Rata-rata Frekuensi Jenis Lamun

\begin{tabular}{|c|c|c|c|c|}
\hline \multirow{2}{*}{ Jenis Lamun } & \multicolumn{3}{|c|}{ Stasiun } & \multirow[t]{2}{*}{ Rata-rata } \\
\hline & I & II & III & \\
\hline $\begin{array}{l}\text { Enhalus } \\
\text { acoroides* } \\
\text { halophila }\end{array}$ & 3.00 & 3.00 & 2.75 & 2.92 \\
\hline $\begin{array}{l}\text { ovalis } \\
\text { Cyomodocea }\end{array}$ & 0.00 & 0.50 & 0.00 & 0.17 \\
\hline rotundata & 0.00 & 0.00 & 1.00 & 0.33 \\
\hline Jumlah & 3.00 & 3.50 & 3.75 & 3.42 \\
\hline
\end{tabular}

3. Penutupan Jenis (presentase tutupan) dan Penutupan Relatif

Nilai penutupan relatif tertinggi pada seluruh stasiun pengamatan didominasi oleh jenis lamun yang berukuran besar yaitu E. acoroides. Sedangkan nilai penutupan relatif terendah adalah jenis $C$. rotundata. Tingginya nilai tutupan relatif sejalan dengan tingginya nilai tutupan jenis lamun tersebut, jenis E. acoroides memiliki nilai tutupan yang tinggi, karena memiliki ukuran daun yang lebih besar, jika dibandingkan dengan dua jenis lamun lainnya. Sedangkan jenis lamun yang berukuran lebih kecil, relatif akan memiliki nilai persentase penutupan yang lebih kecil pula.
Tabel 5. Rata-Rata Penutupan Jenis (Ci) Lamun

\begin{tabular}{lrccc}
\hline \multirow{2}{*}{ Jenis Lamun } & \multicolumn{3}{c}{ Stasiun } & $\begin{array}{c}\text { Rata- } \\
\text { rata }\end{array}$ \\
\cline { 2 - 4 } & I & II & III & \\
\hline $\begin{array}{l}\text { Enhalus } \\
\begin{array}{l}\text { acoroides* } \\
\text { halophila }\end{array}\end{array}$ & 75.00 & 2.68 & 6.88 & 28.19 \\
$\begin{array}{l}\text { ovalis } \\
\begin{array}{l}\text { Cyomodocea } \\
\text { rotundata }\end{array}\end{array}$ & 0.00 & 1.34 & 0.00 & 0.45 \\
\hline Jumlah & 0.00 & 0.00 & 0.83 & 0.28 \\
\hline
\end{tabular}

Berdasarkan hasil analisis sidik ragam (ANOVA) penutupan jenis lamun antar stasiun pada jenis lamun E.acoroides memberikan perbedaan yang nyata $(\mathrm{p}<0,05)$ sedangkan pada jenis H.ovalis dan C.rotuundata tidak memberikan perbedaan nyata $(\mathrm{p}>0,05)$

Berdasarkan Tabel 5 untuk kriteria status padang lamun (Keputusan Menteri Lingkungan Hidup No. 200 Tahun 2004), maka dapat disimpulkan bahwa kondisi lamun berdasarkan penutupan di Pulau Pannikiang hanya pada stasiun I yang termasuk kondisi sehat/kaya (> $60 \%$ ) sedangkan pada stasiun II dan III termasuk kondisi miskin $(<29,9 \%)$. Secara keseluruhan rata-rata penutupan lamun ketiga stasiun pengamatan yaitu $28,91 \%$ yang menunjukkan kondisi miskin, hal ini diduga karena kurangnya stasiun pengamatan dengan pulau yang cukup 
panjang. Berdasarkan hasil citra panjang wilayah pulau $2899 \mathrm{~m}$ dan lebar $344 \mathrm{~m}$ dengan luas daratan pulau 94,5 ha (barrukab.go.id/site/assets/files/ 1567/potensi_obyek_wisata_kabupaten_ barru.pd)

\section{Indeks Nilai Penting}

Hasil perhitungan (Tabel 6) menunjukkan bahwa lamun jenis $E$. acoroides memiliki INP tertinggi pada stasiun I dekat pemukiman $300 \%$, pada stasiun II habitat karang tertinggi pada jenis E. acoroides sebesar $245 \%$ kemudian disusul $H$. ovalis $55 \%$ dan stasiun III dekat habitat mangrove $E$. acoroides sebesar $238.98 \%$ dan $C$. rotundata $61.02 \%$. Hal ini berarti secara ekologis, jenis lamun E. acoroides memiliki peranan yang sangat penting terhadap struktur komunitas lamun di Pulau Pannikiang.

Tabel 6. INP Lamun di Pulau Pannikiang

\begin{tabular}{lrrr}
\hline \multirow{2}{*}{ Jenis Lamun } & \multicolumn{3}{c}{ Stasiun } \\
\cline { 2 - 4 } & \multicolumn{1}{c}{ I } & II & III \\
\cline { 2 - 4 } & 300.00 & 245.00 & 238.98 \\
\hline $\begin{array}{l}\text { Enhalus } \\
\text { acoroides } *\end{array}$ & 0.00 & 55.00 & 0.00 \\
$\begin{array}{l}\text { Halophila } \\
\text { ovalis }\end{array}$ & 0.00 & 0.00 & 61.02 \\
$\begin{array}{l}\text { Cyomodocea } \\
\text { rotundata }\end{array}$ & 300.00 & 300.00 & 300.00 \\
\hline Jumlah & & & \\
\hline
\end{tabular}

\section{Produktifitas Lamun}

Hasil perhitungan menunjukkan bahwa rata-rata biomassa tertinggi pada seluruh stasiun pengamatan didominasi oleh jenis lamun E. acoroides dengan nilai rata-rata biomassa tertinggi berada pada stasiun III $5.06 \mathrm{gbk} / \mathrm{m}^{2}$, diikuti oleh stasiun I $4.22 \mathrm{gbk} / \mathrm{m}^{2}$ dan $3.84 \mathrm{gbk} / \mathrm{m}^{2}$ pada stasiun II. Sedangkan jenis lamun yang memiliki nilai terendah adalah jenis $H$. ovalis $0.01 \mathrm{gbk} / \mathrm{m}^{2}$ pada stasiun II dan C. rotundata $0.50 \mathrm{gbk} / \mathrm{m}^{2}$ pada stasiun III. Berdasarkan hasil analisis sidik ragam (ANOVA) biomassa lamun antar stasiun pada jenis lamun E.acoroides memberikan perbedaan yang nyata $(\mathrm{p}<0,05)$ sedangkan pada jenis H.ovalis dan C.rotundata tidak memberikan perbedaan nyata $(p>0,05)$.

\section{Parameter Fisika Kimia Perairan}

\section{a. Kualitas Air}

Kualitas perairan di Pulau Pannikiang secara umum disajikan pada Tabel 7.

Tabel 7. Nilai parameter kualitas air

\begin{tabular}{llrrc}
\hline \multirow{2}{*}{ Parameter } & \multirow{2}{*}{ Satuan } & \multicolumn{3}{c}{ Stasiun } \\
\cline { 3 - 5 } Suhu & \multicolumn{1}{c}{ I } & \multicolumn{1}{c}{ II } & III \\
\hline & & 26.00 & 30.00 & 29.33 \\
Kedalaman & $\mathrm{Cm}$ & 33. & & \\
Salinitas & $\mathrm{Ppt}$ & 31.33 & 30.00 & 30.00 \\
Oksigen & & & & \\
Terlarut & $\mathrm{mg} / 1$ & 3.69 & 5.52 & 3.56 \\
Kekeruhan & $\mathrm{NTU}$ & 4.70 & 3.94 & 1.76 \\
\hline \multicolumn{5}{l}{ Sumber : Data primer 2018} \\
\end{tabular}


Hasil pengukuran suhu pada bahwa nilai salinitas pada perairan ini keseluruhan stasiun pengamatan rata- masih sesuai untuk kehidupan lamun, rata berkisar antara $26.00-30.00{ }^{\circ} \mathrm{C}$. dan termasuk dalam kriteria untuk Berdasarkan data Tabel 12 rata-rata suhu pertumbuhan lamun yang optimal. pada stasiun I adalah $26.00{ }^{\circ} \mathrm{C}$, stasiun II Seperti yang dikemukakan oleh $30.00{ }^{\circ} \mathrm{C}$, dan stasiun III $29.33{ }^{\circ} \mathrm{C}$. Hal Supriharyono (2009) bahwa salinitas ini disebabkan oleh rentang waktu dalam yang optimal secara umum untuk pengambilan sampel yang dekat pada tiap stasiun yaitu pada pukul 11.0017.00 WITA. Berdasarkan hasil pengamatan dalam penelitian ini nilai kedalaman rata-rata berkisar antara 73.33 - $123.33 \mathrm{~cm}$. Kedalaman lamun pada perairan Pulau Pannikiang menunjukkan perbedaan pada masingmasing stasiun yaitu stasiun I dengan kedalaman $73.33 \mathrm{~cm}$, stasiun II 123.33 $\mathrm{cm}$, dan stasiun III $96.67 \mathrm{~cm}$. Dahuri, et al. (2001) menambahkan distribusi lamun terbatas pada kedalaman yang tidak lebih dari $10 \mathrm{~m}$ dikarenakan lamun membutuhkan intensitas cahaya yang cukup bagi proses fotosintesis di perairan.

Berdasarkan data kualitas air yang diperoleh di lokasi penelitian, nilai salinitas pada seluruh stasiun pengamatan rata-rata berkisar antara 30.00 - 31.33 ppt. Dimana pada stasiun I nilai salinitas $31.33 \mathrm{ppt}$, stasiun II pertumbuhan lamun adalah berkisar antara 25-35 ppt.

Hasil pengukuran DO pada penelitian ini rata-rata berkisar antara 3.56 - $5.52 \mathrm{mg} / \mathrm{l}$. Pada stasiun I 3.69 $\mathrm{mg} / \mathrm{l}$, stasiun II $5.52 \mathrm{mg} / \mathrm{l}$, dan stasiun III $3.56 \mathrm{mg} / 1$. Konsentrasi DO yang terukur pada penelitian ini apabila dibandingkan dengan baku mutu berdasarkan Keputusan Menteri Lingkungan Hidup Nomor 51 Tahun 2004, hanya stasiun II yang masih memenuhi kriteria konsentrasi DO yang dapat menunjang kehidupan biota laut yaitu lebih dari 5 mg/l, sedangkan stasiun I dan stasiun III tidak memenuhi kriteria.

Kekeruhan di perairan Pulau Pannikiang rata-rata berkisar antara 1.76 - 4.70 NTU. Berdasarkan Surat Keputusan Menteri Negara Lingkungan Hidup No. 51 Tahun 2004 Tentang Baku Mutu Air Laut, nilai kekeruhan untuk wisata dan biota laut adalah $<5$ NTU.

30.00 ppt, dan stasiun III 30.00 ppt. Perairan Pulau Pannikiang menunjukkan 


\section{b. Substrat Dasar Perairan}

Tabel 8. Rata-Rata Kandungan Nutrien dan Tipe Substrat

\begin{tabular}{lccc}
\hline \multirow{2}{*}{ Parameter } & \multicolumn{3}{c}{ Stasiun } \\
\cline { 2 - 4 } & I & II & III \\
\hline C- & & & \\
Organik & 3.62 & 3.15 & 4.26 \\
Nitrat & & & \\
(ppm) & 0.75 & 0.75 & 0.80 \\
Fosfat & & & \\
(ppm) & 17.16 & 13.19 & 12.49 \\
pH & 6.98 & 6.87 & 7.08 \\
Jenis & Pasir & & Pasir \\
Sedimen & berlembung & Pasir & berlempung \\
Pasir & 88 & 89 & 84 \\
Debu & 5 & 5 & 7 \\
Liat & 7 & 7 & 10 \\
\hline Total & 100 & 100 & 100 \\
\hline \multicolumn{3}{r}{}
\end{tabular}

Hasil analisis pada seluruh stasiun pengamatan, bahwa persentase nilai bahan organik tertinggi berada pada stasiun III (mangrove) sebesar $4.26 \%$, diikuti oleh stasiun I (pemukiman) 3.62 $\%$ dan persentase bahan organik terendah terdapat pada stasiun II (karang) $3.15 \%$. Berdasarkan hasil analisis sidik ragam (ANOVA) kandungan bahan organik lamun antar stasiun pada ketiga jenis lamun tidak memberikan perbedaan yang nyata $(\mathrm{p}>0,05)$.

Kandungan bahan organik $\mathrm{N}$ dan $\mathrm{P}$ substrat pada penelitian ini berbeda antar stasiun, dimana kandungan $\mathrm{P}$ lebih besar dibandingkan dengan kandung $\mathrm{N}$. Berdasarkan hasil analisis sidik ragam
Hasil analisis substrat pada seluruh stasiun ditampilkan pada Tabel 8.

(ANOVA) kandungan fosfat dan nitrat antar stasiun pada ketiga jenis lamun tidak memberikan perbedaan yang nyata $(\mathrm{p}>0,05)$.

Nilai $\mathrm{pH}$ tanah yang telah diukur diperoleh kisaran antara 6.87 - 7.08 . Dari hasil pengukuran, $\mathrm{pH}$ tertinggi diperoleh pada stasiun III dengan nilai 7.08. Sedangkan $\mathrm{pH}$ terendah diperoleh pada stasiun II dengan nilai 6.87 . Kisaran $\mathrm{pH}$ ini masih bersifat netral karena semua nilainya mendekati nilai 7 . Berdasarkan hasil analisis sidik ragam (ANOVA) kandungan $\mathrm{pH}$ substrat antar stasiun pada ketiga jenis lamun tidak memberikan perbedaan yang nyata $(\mathrm{p}>0,05)$.

\section{KESIMPULAN}

Berdasarkan hasil penelitian dapat disimpulkan bahwa komunitas padang lamun di Pulau Pannikiang terdiri dari jenis Enhalus acoroides, Halophila ovalis, dan Cymodocea rotundata, yang didominasi oleh Enhalus acoroides. Jenis substratnya pasir berlumpur dan dilihat dari kandungan nutrientnya, dapat dikategorikan dalam kondisi perairan yang sesuai untuk kehidupan lamun. Hasil perhitungan INP 
didominasi oleh Enhalus acoroides, sedangkan produktivitas (biomassa) tertinggi terdapat pada jenis Enhalus acoroides.

\section{SARAN}

Perlu diadakan penelitian lanjutan terkait penyediaan data dan informasi spasial mengenai kondisi padang lamun di Pulau Pannikiang sebagai acuan dalam usaha pengelolaan di wilayah ini.

\section{UCAPAN TERIMA KASIH}

Tulisan ini merupakan bagian dari penelitian Tesis dan penulis mengucapkan terima kasih kepada Ketua Prodi dan Direktur Pasca Sarjana yang telah memberi kesempatan untuk melanjutkan pendidikan di PPS UMI.

\section{DAFTAR PUSTAKA}

Akbar H, Jailani J, Suyatna I, Destilawaty D, Putra SA, Ambalika I. 2018. Check list of the marine commercial and reef fishes of Belitung Timur, Bangka Belitung Islands, Indonesia. Aceh Journal of Animal Science 3(2): 69-83.

DOI: 10.13170/ajas.3.2.12220.

Bjork, M., F.T. Short, E. Mcleod \& S. Beer. 2008. Managing Seagrasses for Resilience to Climate Change. IUCN. Switzerland. 55 hal.

Brower, J. E. and J. H. Zar. 1977. Field and Laboratory Methods For
General Ecology. Brown Company Publishers, Iowa.

Brower JE, Zar JH, \& von Ende CN. 1998. Field and laboratory method from general ecology. 3rd (ed). WM. C. Brown Publishers, Dubuque. Lowa. 273p.

Dahuri R, Rais J, Ginting SP, Sitopu MJ. 2001. Pengelolaan Sumberdaya Wilayah Pesisir dan Lautan Secara Terpadu. Jakarta. Pradnya Paramita.nFachrul MF. 2007. Metode Sampling Bioekologi. Bumi Aksara. Jakarta.

English, S., Wilkinson, C., Baker, V. 1994. Survey Manual for Tropical Marine Resources. Australian Institute of Marine Science. Townsville.

Faisal TM, Akbar H, Putriningtias A, Putra SA. 2019. Short Communication: Community structure of prawns (Decapoda: Penaeidae and Palaemonidae) in mangrove inlets of Kuala Langsa, Aceh, Indonesia. Biodiversitas 20(5): 1306-1311. DOI: 10.13057/biodiv/d200509.

Ganefiani A, Suryanti S, Latifah N. 2019. Potensi Padang Lamun Sebagai Penyerap Karbon di Perairan Pulau Karimunjawa, Taman Nasional Karimunjawa. Saintek Perikanan 14(2): 115-122.

Hartini H, Lestarini Y. 2019. Pemetaan Padang Lamun Sebagai Penunjang Ekowisata di Kabupaten Lombok Timur. Jurnal Biologi Tropis 19(1): $1-7 . \quad$ DOI: 10.29303/jbt.v19i1.927. 
Irawan A. 2017. Koleksi Lamun LIPI Ambon 2008-2015. Lonawarta XXIII(2): 1-21.

Latuconsina $\mathrm{H}$, Padang $\mathrm{H}$, Ena AM. 2019. Iktiofauna di Padang Lamun Pulau Tatumbu Teluk Kotania, Seram Barat-Maluku. Jurnal Agribisnis Perikanan 12(1): 93104. DOI: $10.29239 /$ j.agrikan. 12.1.93-104

McKenzie LJ. 2003. Guidelines for the rapid assessment and mapping of tropical seagrass habitats. QFS, NFC, Caims. 46 pp.

McKenzie LJ \& Yoshida RL. 2009. Seagrass-Watch: Proceeding of a workshop for monitoring seagrass habitat in Indonesia. The Nature Conservacy, Coral Triangle Center, Sanur, Bali, 9th May 2009.Seagrass-Watch HQ Cairns. $56 \mathrm{p}$.

Menteri Negara KLH. 2004. Keputusan Menteri Negara Lingkungan Hidup No. 51 Tahun 2004 Tentang Baku Mutu Air Laut Untuk Biota Laut. Jakarta.
Oktawati NO, Sulistianto E, Fahrizal W, Maryanto F. 2018. Nilai Ekonomi Ekosistem Lamun di Kota Bontang. EnviroScienteae 14(3): 228-236.

Putriningtias A, Faisal TM, Komariyah S, Bahri S, Akbar H. 2019. Keanekaragaman Jenis Kepiting di Ekosistem Hutan Mangrove Kuala Langsa, Kota Langsa, Aceh. Jurnal Biologi Tropis 19(1): 101-107. DOI: 10.29303/jbt.v19i1.1074.

Supriharyono. 2009. Konservasi Ekosistem Sumberdaya Hayati. Pustaka Pelajar. Yogyakarta.

Supriyadi IH, Iswari MY, Suyarso. 2018. Kajian Awal Kondisi Padang Lamun di Perairan Timur Indonesia. Jurnal Segara 14(3): 169-177. DOI: 10.15578/segara.v14i3.6887

Zieman, J.C. and ng. wetzel 1980. Productivity in seagrasses: methods and rates. In: Handbook of seagrass biology: an ecosystem perspective. (R.C. Phillips and C.P. McRoy eds.) Garland Publ.Inc. New York.: 87-115. 